\title{
A retrospective cohort study on the association between poor sleep quality in junior high school students and high hemoglobin A1c level in early adults with higher body mass index values
}

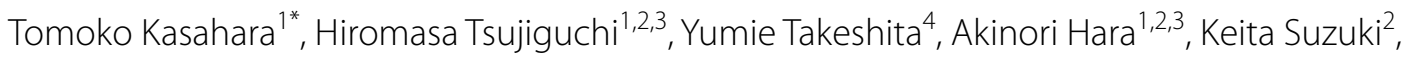
Nobuhiko Narukawa', Koichiro Hayashi ${ }^{1}$, Masateru Miyagi ${ }^{1}$, Atsushi Asai ${ }^{1}$, Yohei Yamada' , Haruki Nakamura', Fumihiko Suzuki ${ }^{2,5}$, Kim-Oanh Pham², Toshio Hamagishi², Masaharu Nakamura², Aki Shibata², Yukari Shimizu ${ }^{2,6}$, Thao Thi Thu Nguyen ${ }^{2,7}$, Sakae Miyagi ${ }^{8}$, Yasuhiro Kambayashi ${ }^{9}$, Takayuki Kannon ${ }^{3,10}$, Atsushi Tajima ${ }^{3,10}$, Hirohito Tsuboi ${ }^{11}$, Tadashi Konoshita ${ }^{12,13}$, Toshinari Takamura ${ }^{4}$ and Hiroyuki Nakamura 1,2,3

\begin{abstract}
Background: Few epidemiological studies have been performed to clarify the association between glucose metabolism disorders in early adults (20 years old) and physiological and environmental factors, including body mass index (BMI) in junior high school days. Therefore, we examined the association between hemoglobin A1c (HbA1c) level and body size (BMI) in early adulthood and lifestyles, including sleep habits and BMI in junior high school days in Shika town, a small town in Japan, by conducting a retrospective cohort study.

Methods: We examined the HbA1c levels and body size (BMI) of 99 early adults who turned 20 years old between 2016 and 2020 and were residing in Shika town, Ishikawa Prefecture. We obtained the information on lifestyles and living environment factors, including BMI, from a questionnaire survey conducted among the subjects during their junior high school days (13-15 years old) from 2009 to 2013.
\end{abstract}

Results: No correlations were observed between the HbA1c levels and the BMI values of the early adults. A two-way analysis of covariance (with the HbA1c levels and BMI values of the early adults as main factors) of the body size and lifestyle habits of the junior high school students revealed that "sleep quality in junior high school" was significantly poorer in the high HbA1c group than in the low HbA1c group in the early adults with high BMI values only. This result was also supported by the logistic regression analysis result.

Conclusions: The present results indicate that poor sleep quality in junior high school was associated with the high $\mathrm{HbA1c}$ levels of the early adults with higher BMI values, which suggests that good sleep quality in junior high school

\footnotetext{
*Correspondence: kenshoudou@mx3.et.tiki.ne.jp

${ }^{1}$ Department of Hygiene and Public Health, Graduate School

of Advanced Preventive, Medical Sciences, Kanazawa University, 13-1

Takara-machi, Kanazawa, Ishikawa 920-8640, Japan

Full list of author information is available at the end of the article
}

(c) The Author(s) 2022. Open Access This article is licensed under a Creative Commons Attribution 4.0 International License, which permits use, sharing, adaptation, distribution and reproduction in any medium or format, as long as you give appropriate credit to the original author(s) and the source, provide a link to the Creative Commons licence, and indicate if changes were made. The images or other third party material in this article are included in the article's Creative Commons licence, unless indicated otherwise in a credit line to the material. If material is not included in the article's Creative Commons licence and your intended use is not permitted by statutory regulation or exceeds the permitted use, you will need to obtain permission directly from the copyright holder. To view a copy of this licence, visit http://creativecommons.org/licenses/by/4.0/. The Creative Commons Public Domain Dedication waiver (http://creativeco mmons.org/publicdomain/zero/1.0/) applies to the data made available in this article, unless otherwise stated in a credit line to the data. 
prevents the development of hyperglycemia. However, the present study did not find any relationship between earlyadult $\mathrm{BMI}$ and $\mathrm{HbA} 1 \mathrm{c}$ level.

Keywords: BMI, Glycated hemoglobin, Adolescent behavior, Sleep quality, Longitudinal study

\section{Background}

The prevalence of type 2 diabetes (T2DM) in adolescents and young adults is markedly increasing worldwide [1], particularly in the West Coast of the United States and Southeast Asia [2]. Environmental factors such as obesity, unhealthy diet, psychological stress, and physical inactivity, in addition to genetic factors, contribute to the development of T2DM [3-5]. Obesity has been identified as one of the contributing factors to T2DM. Although the rate of weight gain in Japanese people has plateaued, the prevalence of T2DM continues to increase [3, 6-8]. The mean body weight of the youth of Japan peaked in 1998-2006 and subsequently stabilized [7, 8]. Only a few longitudinal studies have demonstrated that lifestyle habits and body mass index (BMI) values of middle school students are risk factors of abnormal glucose metabolism [9, 10]. In 2016, Xi et al. [9] reported that low birth weight and central obesity in adolescents influenced the subsequent development of T2DM in young adults in China, which suggests that body weight control in the young effectively prevent and control T2DM in adulthood. Cross-sectional studies investigated sleep quality in the young as a risk factor of T2DM in adulthood [11, 12]. A relationship was found between sleep quality and insulin resistance that was dependent on adiposity [12]. However, no retrospective cohort study has yet been conducted to elucidate the relationship between sleep quality in the young and glucose metabolism in early adulthood. T2DM is partly caused by genetic factors and mainly by eating habits. Therefore, hypothesizing the effect of the living environment, BMI,and lifestyle factors such as sleep in junior high school students on their subsequent glucose metabolism, we conducted a retrospective cohort study using early adulthood hemoglobin A1c (HbA1c) level as the index.

\section{Methods}

\section{Subjects}

We conducted a retrospective study in Shika town, a rural area in the Noto Peninsula, Ishikawa Prefecture, Japan. Five hundred and forty-one people who participated in a self-reported questionnaire survey when they were enrolled in junior high schools in Shika between 2009 and 2013 were invited to the coming-of-age ceremony (2016-2020). A total of 405 people were excluded from the study if they did not attend the coming-of-age ceremony (85), did not receive a blood test for examining
HbA1c, or agree to participate (320). Hence, 136 people participated in this study. However, during the analysis, 37 people were excluded ( 26 because of insufficient information, height, weight and HbA1c at the time of the examination and 11 of the questionnaire in junior high school). Figure 1 shows the inclusion criteria.

\section{BMI and lifestyle in junior high school}

We collected data on body size assessed by school nurses, including junior high school height and weight, from school health records. BMI is calculated as weight $(\mathrm{kg})$ divided by height squared $\left(\mathrm{m}^{2}\right)$ [13]. We compared the BMI values and lifestyles of the analyzed and nonanalyzed subjects. Lifestyle habits were evaluated using a self-administered questionnaire based on the 2007 National Health and Nutrition Examination Survey by the Ministry of Health, Labour, and Welfare of Japan [11]. The questionnaire included items on dietary habits (snacking habit: less than once a week, every 2 or 3 days, or every day; dinner companion: none, siblings, or family), exercise habits (playing sports for one year or more: yes, no), sleeplessness, sleep duration $(>9,8-9,7-8$, $6-7,5-6$, or $<5 \mathrm{~h}$ ), sleep quality, and psychological stress (none at all, a little, some, or much). Sleep quality was evaluated using questions regarding whether the students had a sufficient amount of sleep to feel rested; the items were scored from 1 to 4 (1: sufficient, 2: to some extent, 3: poor, and 4: insufficient). Of these questions, the items on snacking habits, sleep duration, sleep quality, psychological stress, and family history of diabetes were adapted from the Ministry of Health, Labour, and Welfare's National Health and Nutrition Survey $[14,15]$. Furthermore, we added the question items on playing sports for one year or more, dinner companion, and the arranged items are snacking habits.

\section{Blood glucose levels and BMI in early adulthood}

Early-adult HbA1c levels were measured using a quantitative immunoturbidimetric assay (A1C Gear System, Sakae Corporation, Gunma, Japan) using $1 \mu$ of blood obtained from the fingertips of the subjects in early adult (20 years old). Information on height and weight was collected using a self-administered questionnaire. Body size was evaluated using early-adult BMI in the same manner as the junior high school age. The subjects were classified into two groups based on early-adult HbA1c levels as follows: a low early-adult HbA1c group $(\leq 5.4 \%)$ and a high 


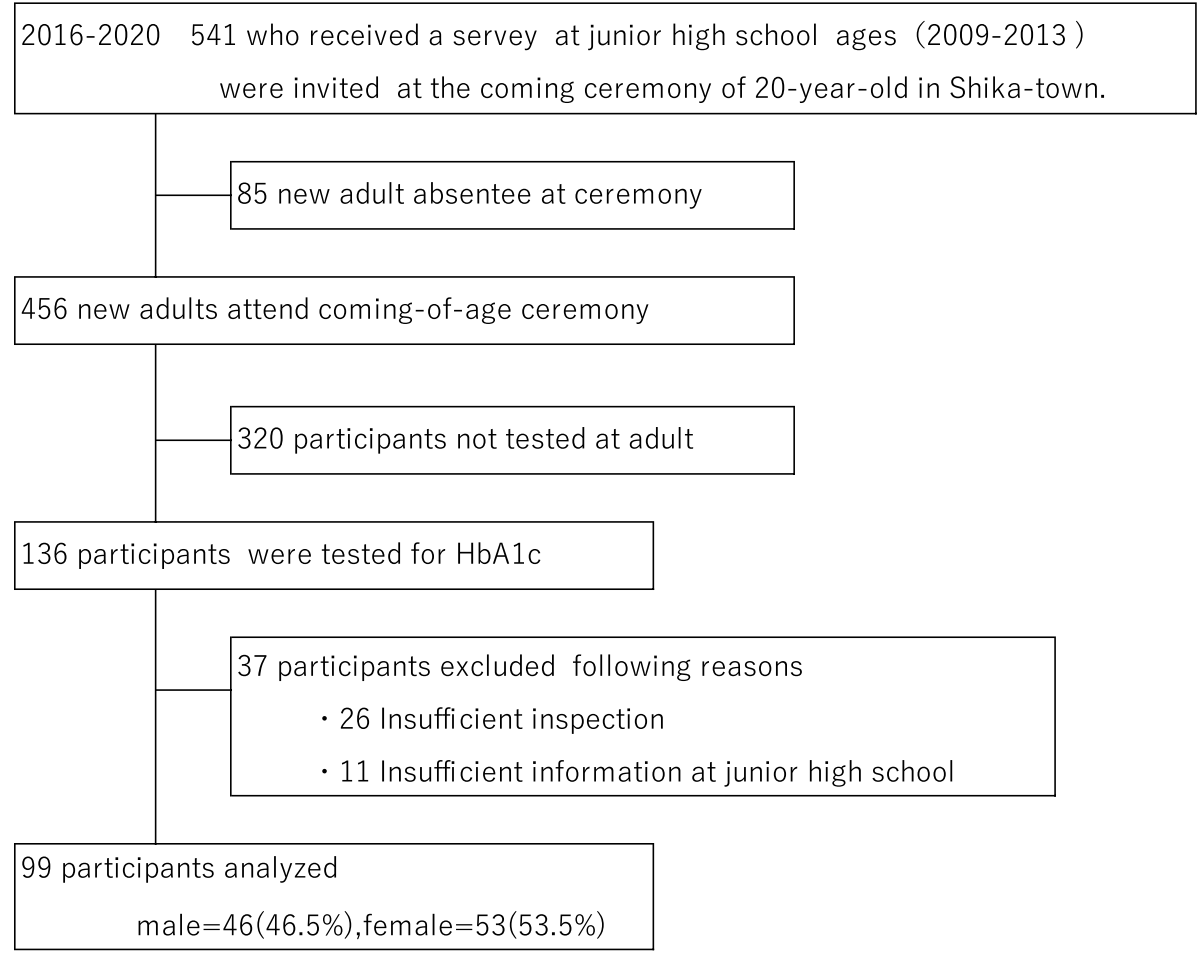

Fig. 1 Participant recruitment chart

early-adult HbA1c group (>5.4\%). The cutoff point was defined according to the upper limit of the nondiabetic level in Japan [16-18]. The subjects were simultaneously categorized into two groups according to early-adult BMI as follows: a low early-adult BMI group $(\leq 22 \mathrm{~kg}$ / $\mathrm{m}^{2}$ ) and high early-adult BMI group $\left(>22 \mathrm{~kg} / \mathrm{m}^{2}\right)$. Earlyadult BMI of $22 \mathrm{~kg} / \mathrm{m}^{2}$ is considered to have the lowest risk of lifestyle-related diseases by the Japanese Ministry of Health, Labour, and Welfare $[19,20]$.

\section{Statistical analysis}

In the comparison of junior high school BMI/lifestyle between the 99 analyzed and 442 nonanalyzed subjects, the Student $t$ test was used for continuous variables and the chi-square test was used for categorical variables.

A two-way analysis of covariance (ANCOVA) with adjustment for sex was used to examine the main effects of early-adult HbA1c level and BMI and their interaction with junior high school lifestyles. Multiple logistic regression analysis was performed to examine HbA1c levels after stratifying HbA1c levels, BMI values, and sleep qualities. Furthermore, a hierarchical regression model was applied to adjust for confounders. The Japanese version of the IBM SPSS Statistics Ver. 26 software for Windows (IBM, Armonk, NY, USA) was used for the statistical analyses. The significance level was set at $5 \%$.

\section{Ethical consideration}

This study was approved by the Ethics Committee of Kanazawa University (No. 1939, 1940). Written informed consent was obtained from all the subjects. The survey in junior high school was also conducted within the scope of the School Health and Safety Law in Japan.

\section{Results}

Subjects' characteristics

Ninety-nine subjects consisting of 46 males (46.5\%) and 53 females $(53.5 \%)$ were included in the study. Table 1 shows the subjects' characteristics and body sizes. The early-adult BMI (20 years old) of males were significantly higher than that of the female $(p=0.001)$. No differences in HbA1c level $(p=0.124)$ and diabetic family history $(p=0.445)$ were found.

\section{Comparison of BMI and environmental factors between the 99 analyzed and 424 nonanalyzed junior high school students}

Table 2 shows a comparison of BMI and lifestyle between the final analyzed $(n=99)$ and nonanalyzed junior high school students $(n=442)$. All the items, including BMI, were not significantly different between the analyzed and nonanalyzed students. The 99 subjects' height and weight in junior high school and early adulthood were 
Table 1 Subjects' characteristics

\begin{tabular}{|c|c|c|c|c|c|c|c|}
\hline & \multicolumn{2}{|c|}{ Total $(n=99)$} & \multicolumn{2}{|c|}{ Males $(n=46)$} & \multicolumn{2}{|c|}{ Females $(n=53)$} & \multirow[t]{2}{*}{$p$ value } \\
\hline & Mean & SD & Mean & SD & Mean & SD & \\
\hline Age & 19.91 & 0.41 & 19.89 & 0.43 & 19.92 & 0.39 & 0.687 \\
\hline BMl in early adults $\left(\mathrm{kg} / \mathrm{m}^{2}\right)$ & 21.96 & 3.87 & 23.43 & 4.95 & 20.68 & 1.88 & 0.001 \\
\hline HbA1c level (\%) & 5.24 & 0.30 & 5.29 & 0.28 & 5.19 & 0.32 & 0.124 \\
\hline Family history of diabetes, & $34(34.3)$ & & $14(30.40)$ & & $20(37.70)$ & & 0.445 \\
\hline
\end{tabular}

$n(\%)^{\mathrm{a}}$

The $p$ values were from the Student $t$ test for continuous variables and chi-square test for categorical variables. The $p$ values $<0.05$ are in bold. The continuous variables are presented as mean (SD). Abbreviation: BMI body mass index. ${ }^{\text {a } 1: \text { yes, } 2 \text { : no }}$

Table 2 Comparison of BMl and environmental factors between the analyzed and nonanalyzed junior high school students

\begin{tabular}{|c|c|c|c|c|c|}
\hline & \multirow{2}{*}{\multicolumn{2}{|c|}{$\begin{array}{l}\text { Analyzed subjects } \\
\text { all }(n=99)\end{array}$}} & \multirow{2}{*}{\multicolumn{2}{|c|}{$\begin{array}{l}\text { Non-analyzed subjects } \\
\text { all }(n=442)\end{array}$}} & \multirow[t]{3}{*}{$p$ value } \\
\hline & & & & & \\
\hline & Mean & SD & Mean & SD & \\
\hline Sex (male), n (\%) & $46(46.5 \%)$ & & $211(47.7 \%)$ & & 0.819 \\
\hline Height (cm) & 156.50 & 6.73 & 157.94 & 7.63 & 0.084 \\
\hline Weight (kg) & 49.04 & 11.34 & 50.10 & 10.59 & 0.375 \\
\hline $\mathrm{BMI}\left(\mathrm{kg} / \mathrm{m}^{2}\right)$ & 19.87 & 3.42 & 19.98 & 3.41 & 0.764 \\
\hline Playing sports for $>1$ year, $\mathrm{n}(\%)^{\mathrm{a}}$ & $85(85.90)$ & & $326(76.7 \%)$ & & 0.130 \\
\hline Snacking habits ${ }^{\mathrm{b}}$ & 2.08 & 0.74 & 1.93 & 0.72 & 0.064 \\
\hline Dinner companion ${ }^{c}$ & 2.89 & 0.45 & 2.84 & 0.50 & 0.416 \\
\hline Sleep duration ${ }^{d}$ & 3.19 & 0.98 & 3.17 & 1.14 & 0.836 \\
\hline Sleep quality ${ }^{e}$ & 1.91 & 0.69 & 1.98 & 0.74 & 0.401 \\
\hline Psychological stress ${ }^{f}$ & 2.26 & 0.95 & 2.45 & 0.91 & 0.064 \\
\hline
\end{tabular}

The $p$ values were from the Student $t$ test for continuous variables and chi-square test for categorical variables. The $p$ values $<0.05$ are in bold. Continuous variables are presented as mean (SD). Abbreviation: BMI body mass index

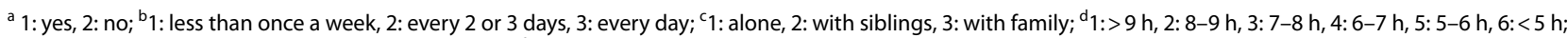

${ }^{e} 1$ : sufficient, 2 : to some extent, 3 : poor, 4 : insufficient; ${ }^{f} 1$ : none at all, 2 : little, 3 : some, 4 : much

not significantly different from the Japanese average values $[21,22]$ (Table S-1).

\section{Comparison of the BMI/environmental factors in junior high school between the early-adult $\mathrm{HbA1c}$ and BMI groups}

Table 3 shows the results of the two-way ANCOVA with the early-adult HbA1c and BMI groups as fixed factors, sex as a covariate for body size/living environment, and junior high school lifestyle as a dependent variable. When the low early-adult HbA1c group was subdivided into two groups based on early-adult BMI, there were 50 participants in the low-BMI group and 27 in the high-BMI group. The subdivision of the high early-adult HbA1c group into two groups based on the early-adult BMI resulted in 15 participants in the low early-adult BMI group and 7 in the high-early-adult BMI group. The early-adult HbA1c group showed that "sleep quality" had a significant main effect $(p<0.001)$. In the high earlyadult BMI group, "sleep quality" was significantly lower in the high than in the low early-adult HbA1c group $(p=0.001$, the Bonferroni test; Figure S-1). Regarding junior high school lifestyle, a significant interaction was observed for "sleep quality" between the early-adult HbA1c and BMI groups $(p=0.024)$.

\section{Logistic regression analysis of sleep in junior high school for early-adult $\mathrm{HbA} 1 \mathrm{c}$ levels}

After stratification according to early-adult BMI, we examined the effects of sleep in junior high school on early-adult HbA1c level by using a multiple logistic regression analysis, which included sex, "sleep quality," exercise habits, snacking habits in junior high school, and family history of T2DM as independent variables (Table 4). Although junior high school sleep quality was not a significant variable in any model in the low earlyadult BMI group, it significantly contributed to earlyadult HbA1c level in any models in the high early-adult BMI group (OR: $10.928 ; 95 \%$ CI: $1.378-86.691 ; p=0.024$ ). These results imply that higher early-adult HbA1c level 


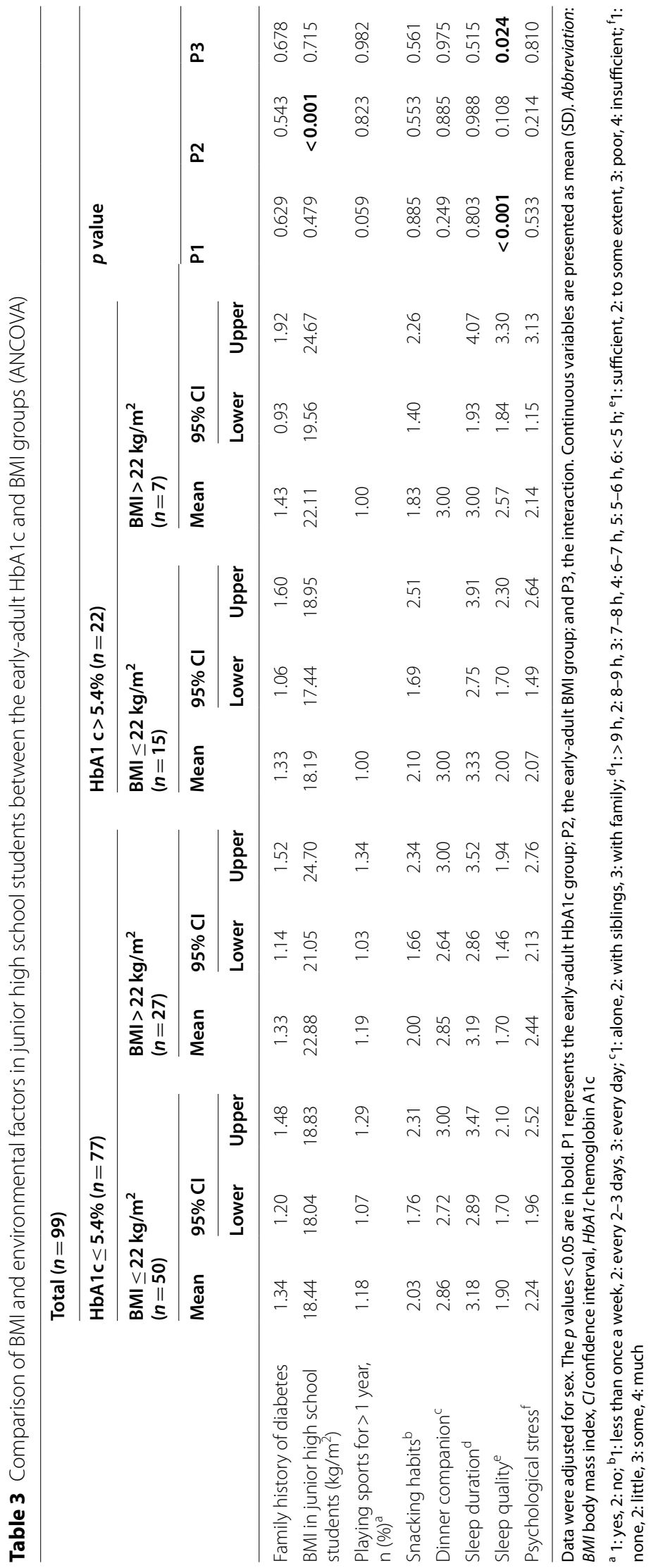


Table 4 A logistic regression analysis of early-adult hemoglobin A1c (HbA1c) levels

\begin{tabular}{|c|c|c|c|c|c|c|c|c|}
\hline & \multicolumn{4}{|c|}{$\mathrm{BMI} \leq 22 \mathrm{~kg} / \mathrm{m}^{2}$} & \multicolumn{4}{|c|}{$\mathrm{BMI}>22 \mathrm{~kg} / \mathrm{m}^{2}$} \\
\hline & \multirow[t]{2}{*}{ OR } & \multicolumn{2}{|l|}{$95 \% \mathrm{Cl}$} & \multirow[t]{2}{*}{$p$ value } & \multirow[t]{2}{*}{ OR } & \multicolumn{2}{|l|}{$95 \% \mathrm{Cl}$} & \multirow[t]{2}{*}{$p$ value } \\
\hline & & Lower & Upper & & & Lower & Upper & \\
\hline Model 1 & 1.506 & 0.599 & 3.783 & 0.384 & 7.297 & 1.297 & 41.048 & 0.024 \\
\hline Model 2 & 1.361 & 0.545 & 3.398 & 0.509 & 6.224 & 1.128 & 34.323 & 0.036 \\
\hline Model 3 & 1.362 & 0.544 & 3.412 & 0.510 & 10.560 & 1.335 & 83.525 & 0.025 \\
\hline Model 4 & 1.367 & 0.543 & 3.437 & 0.507 & 10.928 & 1.378 & 86.691 & 0.024 \\
\hline
\end{tabular}

Model 1: sex and sleep quality in junior high school students; Model 2: sex, sleep quality, playing sports for one year or more in junior high school students; Model 3: sex, sleep quality, playing sports for one year or more, and snacking habits in junior high school students; Model 4: sex, sleep quality, playing sports for one year or more, snacking habits in junior high school students, and family history of diabetes. BMI body mass index, OR odds ratio, $\mathrm{Cl}$ confidence interval

was only found in the high early-adult BMI group when junior high school sleep quality was poor, supporting the results of the two-way ANCOVA.

\section{Discussion}

Relationship between early-adult BMI and HbA1c level

A relationship between BMI and HbA1c levels in adulthood has been reported [20, 23-25]. However, this study did not find any relationship between early-adult BMI and HbA1c level. A Chinese twin cohort study with a 6-year follow-up showed that overweight/obesity at baseline was not a risk factor for developing prediabetes/diabetes [26], which is consistent with the findings of another study [27]. The Young Generation Group Health Examination conducted among adults in their $20 \mathrm{~s}$ and $30 \mathrm{~s}$ in Japan revealed that $64 \%$ of subjects in the high HbA1c group had a standard BMI [28], which is in accordance with the present results showing no relationship between HbA1c level and BMI in adulthood. Previous studies demonstrated that East Asians and Asian Americans, even those with low BMI values, were more likely to develop T2DM at a young age $[29,30]$. The absence of a relationship between early-adult BMI and type 2 diabetes may be explained by the fact that the peak height growth in adolescence continues even at the age of 20 years, resulting in no increase in BMI [31].

\section{Relationship between junior high school sleep quality and early-adult $\mathrm{HbA1c}$ level}

The present results show that junior high school quality of sleep was related to glucose metabolism in early adults. Early-adult HbA1c level was associated with "junior high school sleep quality" in the higher earlyadult BMI group, regardless of sex, exercise habits, snacking habits, or family history of T2DM. Many cross-sectional studies have examined the relationship between sleep quality and early-adult HbA1c level [13, 30, 32-34]. This longitudinal study demonstrated a relationship between junior high school sleep quality and early-adult HbA1c level. According to a 12-year prospective cohort study in middle-aged individuals aged between 45 and 65 years in Sweden [35], the relative risk of T2DM was 2.8-fold higher for males with a short sleep time. Furthermore, reduced sleep time was associated with increased susceptibility to metabolic disorders such as obesity, T2DM, and high blood pressure [36]. Experimental studies [37, 38] also demonstrated that decreased leptin level, increased ghrelin level, increased appetite, decreased insulin sensitivity, and increased blood pressure were due to sleep deprivation. Intervention studies [39] designed to increase sleep volumes and improve sleep quality showed that these changes were useful as treatment and primary preventive measures for metabolic disorders [36].

The present results also indicated that poor sleep quality during adolescence resulted in higher earlyadult HbA1c levels in overweight subjects only. A relationship between adolescent sleep quality and subsequent excessive weight gain has been reported [25, 40]. In this study, we found an interaction between early-adult overweight and junior high school sleep quality, with an odds ratio of 10.928 for developing hyperglycemia. This interaction may be explained by the relationship between sleep hormone melatonin level and nutrition. In addition to the correlation between melatonin secretion and the risk of developing T2DM [41], tryptophan, B vitamins, magnesium, zinc, folic acid, and polyunsaturated fatty acids are required for the synthesis of melatonin [41, 42]. Puberty is the most metabolically active period in the lives of young people, during which they require many nutrients such as proteins and minerals, including zinc, iron, magnesium, and vitamins [43]. In this study, the odds ratio for developing hyperglycemia because of sleep quality increased to 10.56 after excluding the effect of snacking habits. Therefore, there seems to be a relationship between snacking habits and sleep quality. This is consistent with a previous study conducted in eight 
cities in China, which demonstrated that a higher total energy intake associated with snacking habits leads to poor sleep quality in junior high school students [44, 45]. Malnutrition associated with an unbalanced diet during adolescence has been shown to be associated with excessive weight gain in subsequent life stages such as early adulthood [46-48]. Therefore, the lack of necessary nutrients, which is associated with poor sleep quality, may contribute to the development of hyperglycemia in early adults who are overweight.

\section{Limitations}

This study has some limitations. The present results, which were obtained from a limited number of students in a small area of Japan, have a selection bias and thus cannot be generalized to other populations. The absence of a relationship between early-adult BMI and HbA1c level in our study might be due to our small sample size of 99 participants. Furthermore, junior high school sleep quality was self-reported in junior high school and was not based on objective indicators.

\section{Conclusion}

The present results indicate that poor sleep quality among junior high school students was associated with high HbA1c levels in early adults with higher BMI values, which suggests that good sleep quality in junior high school prevents the development of hyperglycemia in early adulthood. However, in this study, we did not find any relationship between early-adult BMI and HbA1c level.

\section{Abbreviations}

ANCOVA: Two-way analysis of covariance; BMI: Body mass index; Cl: Confidence interval,; $\mathrm{HbA} 1 \mathrm{c}$ : Hemoglobin A1c; OR: Odds ratio; SD: Standard deviation; T2DM: Type 2 diabetes.

\section{Supplementary Information}

The online version contains supplementary material available at https://doi. org/10.1186/s12902-022-00951-6.

Additional file 1: Table S-1. Height and weight of the subjects (comparison with the Japanese average values).

Additional file 2: Figure S-1. Interaction between the two hemoglobin A1c groups and two BMl groups of early adults.

\section{Acknowledgements}

We would like to express our deep gratitude to junior high school staff in Shika town who co-operated with this research, the commercial and industrial workers of Togi in Shika town, Shika Town Medical Health staff, and staff at the Graduate School of Advanced Preventive Medical Sciences, Kanazawa University Graduate School of Medicine.

\section{Publication}

The authors declare that this manuscript is original, has not been published before, and is not currently being considered for publication elsewhere.
Authors' contributions

T.K (Tomoko Kasahara). Y.T. and T.T conceptualized the study. T.K (Tomoko Kasahara) curated the date. T.K (Tomoko Kasahara) formally analyzed the data. H.N (Hiroyuki Nakamura) received educational and research funds for environmental ecology and public health, funded by the Education and Research Fund, for this study. T.T and H.N (Hiroyuki Nakamura) supported T.K (Tomoko Kasahara) and supervised the analysis of the findings of this work. T.K (Tomoko Kasahara) and H.T (Hiromasa Tsujiguti) conducted the investigation. T.K (Tomoko Kasahara), Y.T, T.T, H.T (Hiromasa Tsujiguti), and H.N (Hiroyuki Nakamura) designed the study method. T.K (Tomoko Kasahara), Y.T, H.T (Hiromasa Tsujiguti), and T.T, H.N (Hiroyuki Nakamura) administered this project. T.T and H.N (Hiroyuki Nakamura) verified the results. T.K (Tomoko Kasahara) wrote the original draft of the manuscript. All authors discussed the results and contributed to the final manuscript. All authors have read and approved the final manuscript.

\section{Authors' information}

After graduating from the Faculty of Pharmaceutical Sciences, Hokuriku University, I completed a master's course at Kanazawa University and am currently enrolled in the Graduate School of Advanced Preventive Medicine, Kanazawa University.

I am a member of the Shika Study research team and school pharmacist in junior high school in Shika town.

\section{Funding}

The cost of materials such as consumables related to the $\mathrm{HbA} 1 \mathrm{c}$ measurements and other surveys was covered by educational and research funds for environmental ecology and public health.

\section{Availability of data and materials}

The data described in the manuscript will be made available upon request application and approval (Kanazawa University Ethics Committee; person in charge:Yuko Katsuragi, pub-jim2@staff.kanazawa-u.ac.jp).

\section{Declarations}

\section{Ethics approval and consent to participate}

The present study was approved by the Ethics Committee of Kanazawa University. (No. 1939, 1940). Written informed consent was obtained from all subjects. The survey in junior high school was also conducted within the scope of the School Health and Safety Law in Japan.

\section{Consent for publication}

Not Applicable.

\section{Competing interests}

Financial disclosure statement

The funders had no role in the study design, data collection and analysis, decision to publish, or preparation of the manuscript.

Nonfinancial disclosure statement

The authors declare no conflicts of interest associated with this manuscript.

\section{Author details}

'Department of Hygiene and Public Health, Graduate School of Advanced Preventive, Medical Sciences, Kanazawa University, 13-1 Takara-machi, Kanazawa, Ishikawa 920-8640, Japan. ${ }^{2}$ Department of Hygiene and Public Health, Graduate School of Medical Science, Kanazawa University, 13-1 Takara-machi, Kanazawa, Ishikawa 920-8640, Japan. ${ }^{3}$ Kanazawa University Advanced Preventive Medical Sciences Research Center, Takara-Machi 13-1, Kanazawa, Ishikawa 920-8640, Japan. ${ }^{4}$ Department of Endocrinology and Metabolism, Graduate School of Medical Sciences, Kanazawa University, 13-1 Takara-machi, Kanazawa, Ishikawa 920-8640, Japan. ${ }^{5}$ Community Medicine Support Dentistry, Ohu University Hospital, Koriyama, Fukushima 963-8611, Japan. ${ }^{6}$ Faculty of Health Sciences, Department of Nursing, Komatsu University, 14-1 Mukaimotoori-Machi, Komatsu, Ishikawa 923-0961, Japan. ${ }^{7}$ Faculty of Public Health, Haiphong University of Medicine and Pharmacy, 180000 Ngo Quyen, Hai Phong, Vietnam. ${ }^{8}$ Innovative Clinical Research Center, Kanazawa University, 13-1 Takara-machi, Kanazawa, Ishikawa 920-8641, Japan. ${ }^{9}$ Department of Public Health, Faculty of Veterinary Medicine, Okayama University of Science, 1-3 Ikoinooka, Imabari, Ehime 794-8555, Japan. ${ }^{10}$ Department 
of Bioinformatics and Genomics, Graduate School of Advanced Preventive, Medical Sciences, Kanazawa University, 13-1 Takara-machi, Kanazawa, Ishikawa 920-8640, Japan. ${ }^{11}$ Institute of Medical, Pharmaceutical \& Health Sciences, Kanazawa University, Kanazawa 920-1192, Japan. ${ }^{12}$ Department of Endocrinology and Metabolism, University of Fukui Hospital, 23-3, Matsuokashimoaizuki, Eiheiji, Fukui 910-1193, Japan. ${ }^{13}$ Third Department of Internal Medicine, University of Fukui Faculty of Medical Sciences, 23-3, Matsuokashimoaizuki, Eiheiji, Fukui 910-1193, Japan.

Received: 9 September 2021 Accepted: 31 January 2022

Published online: 15 February 2022

\section{References}

1. Maternal and fetal genetic effects on birth weight and their relevance to cardio-metabolic risk factors. Available from: https://egg-consortium.org/

2. Lascar N, Brown J, Pattison H, Barnett AH, Bailey CJ, Bellary S. Type 2 diabetes in adolescents and young adults. LANCET Diabetes Endocrinol. 2018;6(1):69-80. https://doi.org/10.1016/S2213-8587(17)30186-9.

3. DeFronzo RA, Ferrannini E, Groop L, Henry RR, Herman WH, Holst JJ, et al. Type 2 diabetes mellitus. Nat Rev Dis Prim. 2015. [Cited 2021 Mar 7];1. Available from:https://pubmed.ncbi.nlm.nih.gov/27189025/

4. Kushiyama A, Yoshida Y, Kikuchi T, Suzawa N, Yamamoto M, Tanaka K, et al. Twenty-year trend of increasing obesity in young patients with poorly controlled type 2 diabetes at first diagnosis in urban Japan. J Diabetes Investig. 2013;4(6):540-5.

5. Scandiffio JA, Janssen I. Do adolescent sedentary behavior levels predict type 2 diabetes risk in adulthood? BMC Public Heal. 2021;21(1):1-9. ([Cited 2021 Jul 29]. Available from:https://doi.org/10.1186/ s12889-021-10948-w).

6. Ministry of Health, Labor and Welfare J. Figure 20-1 Summary of 2017 National Health and Nutrition Survey Results [Internet]. 2018. Available from: https://www.mhlw.go.jp/content/10904750/000351576.pdf.

7. Ministry of Health $L$ and $W-J$. Chart 1-2-8 Status of the number of diabetic patients|2018 White Paper on Health, Labor and Welfare-To create a society where everyone can play an active role by facing disabilities and illnesses|Japanese Ministry of Health, Labor and Welfare. [Cited 2020 Sep 27]. Available from: https://www.mhlw.go.jp/stf/wp/hakusyo/kousei/18/ backdata/01-01-02-08.html

8. Ministry of Health L and W-J. Summary of 2018 National Health and Nutrition Survey Results [Internet]. 2020 [cited 2020 Nov 29]. Available from: https://www.mhlw.go.jp/content/000681200.pdf.

9. Xi B, Cheng H, Chen F, Zhao X, Mi J. Joint effect of birth weight and obesity measures on abnormal glucose metabolism at adulthood. Zhonghua Yu Fang Yi Xue Za Zhi. 50(1):17-22. [Cited 2020 Sep 3]. Available from: https://europepmc.org/article/med/26792498

10. Power C, Thomas C. Changes in BMl, duration of overweight and obesity, and glucose metabolism: 45 years of follow-up of a birth cohort. Diabetes Care [Internet]. 2011;34. Available from: http://care.diabetesjournals.org/ lookup/suppl/doi:https://doi.org/10.2337/dc10-1482/-/DC1.

11. Ministry of Health L and W-J. 2007 National Health and Nutrition Survey Report in JAPAN. Available from: https://www.mhlw.go.jp/bunya/kenkou/ eiyou09/01.html

12. Dutil C, Chaput JP. Inadequate sleep as a contributor to type 2 diabetes in children and adolescents, vol. 7. Nutrition and Diabetes: Nature Publishing Group; 2017.

13. World Health Organization. WHO/Europe / Nutrition - Body mass index - BMI. [Cited 2020 Oct 6]. Available from: https://www.euro.who. int/en/health-topics/disease-prevention/nutrition/a-healthy-lifestyle/ body-mass-index-bmi

14. YOKOYAMA Tetsuji. National Health Promotion Measures in Japan_Health Japan 21_the second term__Journal of the National Institute of Public Health_.indb - 202069010003.pdf [Internet]. 2020;69(1):14-24. Available from: https://www.niph.go.jp/journal/data/69-1/202069010003.pdf.

15 Tsuboyama-Kasaoka N, Takizawa A, Tsubota-Utsugi M, Nakade M, Imai E, Kondo $\mathrm{A}$, et al. Dietary intake of nutrients with adequate intake values in the dietary reference intakes for Japanese. Journal of Nutritional Science and Vitaminology. 2013;59:584-95.

16 Goto A, Noda M, Sawada N, Kato M, Hidaka A, Mizoue T, et al. High hemoglobin A1c levels within the non-diabetic range are associated with the risk of all cancers. Int J Cancer. 2016;138(7):1741-53. ([Cited 2020 Nov 22]. Available from:https://doi.org/10.1002/ijc.29917).

17. Goto A, Noda M, Matsushita Y, Goto M, Kato M, Isogawa A, et al. Hemoglobin A 1c levels and the risk of cardiovascular disease in people without known diabetes a population-based cohort study in japan. Med. 94(17). Available from: https://www.ncbi.n/m.nih.gov/pmc/artic les/PMC4603057/

18. Ikeda F, Doi Y, Ninomiya T, Hirakawa Y, Mukai N, Hata J, et al. Haemoglobin A1c even within non-diabetic level is a predictor of cardiovascular disease in a general Japanese population: The Hisayama Study. Vol. 12, Cardiovascular Diabetology. 2013. Available from: http://www.cardiab. com/content/12/1/164

19. Ministry of Health $L$ and W-J. BMI | e-healthnete(Ministry of Health, Labor and Welfare in JAPAN). [Cited 2020 Nov 22]. Available from: https://www.e-healthnet.mhlw.go.jp/information/dictionary/metab olic/ym-002.html

20. Someya Id Y, Tamura Y, Kohmura Y, Aoki K, Kawai S, Daida H, et al. A body mass index over $22 \mathrm{~kg} / \mathrm{m} 2$ at college age is a risk factor for future diabetes in Japanese men. 2019; Available from: https://doi.org/ 10.1371/journal.pone.0211067

21. Ministry of Health $L$ and $W$. The national health and nutrition survey in Japan,2011 [Internet]. 2011 [Cited 2021 Jul 31]. Available from: https:// www.mhlw.go.jp/bunya/kenkou/eiyou/dl/h23-houkoku.pdf

22. Ministry of Health $L$ and $W$. The National Health and Nutrition Survey in Japan, 2019. 2019 [Cited 2021 Jul 31];1 16-undefined. Available from: https://www.mhlw.go.jp/content/000710991.pdf

23. Barrett-Connor E. Epidemiology, obesity, and non-insulin-dependent diabetes mellitus. Vol. 11. 1989. Available from: http://epirev.oxfordjour nals.org/

24. Lane\&Ping NTN-MTNLW. Relationship Between Obesity and Diabetes in a US AdultPopulation_Findings from the National Health and NutritionExamination Survey, 1999-2006.pdf. 2010.

25 Jarrin DC, Mcgrath JJ, Drake CL. Beyond sleep duration: Distinct sleep dimensions are associated with obesity in children and adolescent's. Int J Obes. 2013;37(4):552-8 (Available from: http:http://www.nature. com/authors/editorial_policies/license.html\#terms).

26. Wang G, Radovick S, Xu X, Xing H, Tang G, Bartell TR, et al. Strategy for early identification of prediabetes in lean populations: New insight from a prospective Chinese twin cohort of children and young adults. Diabetes Res Clin Pract. 2018;146:101-10. https://doi.org/10.1016/j. diabres.2018.10.003.

27. Huang R-C, De Klerk NH, Smith A, Kendall GE, Landau LI, Mori TA, et al. Lifecourse childhood adiposity trajectories associated with adolescent insulin resistance. 2011; Available from: http://care.diabetesjournals. org/lookup/suppl/doi:10.

28. Miyauchi M, Sakuraba K, Fukao K, Suzuki Y. Association of body type and hemoglobin A1c levels and risk of lifestyle-related diseases in young women. Available from: https://www.jstage.jst.go.jp/article/ jisdh/27/4/27_243/_pdf/-char/ja

29. Ma RCW, Chan JCN, Ma R. Type 2 diabetes in East Asians: similarities and differences with populations in Europe and the United States. Ann NY Acad Sci. 1281:64-91. Available from: https://doi.org/10.1111/nyas. 12098.

30 Mokhlesi B, Temple KA, Tjaden AH, Edelstein SL, Nadeau KJ, Hannon TS, et al. The association of sleep disturbances with glycemia and obesity in youth at risk for or with recently diagnosed type 2 diabetes HHS Public Access. Pediatr Diabetes. 2019;20(8):1056-63.

31 Ohlsson C, Bygdell M, Nethander M, Kindblom JM. Early puberty and risk for type 2 diabetes in men. Diabetologia. 2020;63:1141-50.

32. Koren D, O'sullivan KL, Mokhlesi B. Metabolic and glycemic sequelae of sleep disturbances in children and adults HHS Public Access. Curr Diab Rep. 2015;15(1):562.

33. Resnick HE, Redline S, Shahar E, Gilpin A, Newman A, Walter R, et al. Diabetes and sleep disturbances findings from the sleep heart health study. Diabetes Care. 2003;26(3):702-9.

34 Kawakami N, Takatsuka N, Shimizu H. sleep disturbance and onset of type 2 diabetes. Diabetes care. 2004;27(1):282-3 (Available from:https://care.diabetesjournals.org/content/27/1/282).

35. Mallon L, Broman J-E, Hetta J. High Incidence of Diabetes in Men With Sleep Complaints or Short Sleep Duration A 12-year follow-up study of a middle-aged population. 2005. 
36. Gangwisch JE. Epidemiological evidence for the links between sleep, circadian rhythms and metabolism. Obes Rev [Internet]. 2009;10(SUPPL. 2):37-45. ([Cited 2020 Aug 8]. Available from:https://doi.org/10.1111/j. 1467-789X.2009.00663.x).

37. Taheri S, Lin L, Austin D, Young T, Mignot E. Short sleep duration is associated with reduced leptin, elevated ghrelin, and increased body mass index. Froguel P, editor. PLoS Med. 2004 Dec 7 [Cited 2020 Nov 15]; (3):e62. Available from: https://dx.plos.org/https://doi.org/10.1371/ journal.pmed.0010062

38. Spiegel K, Leproult R, Van Cauter E. Impact of sleep debt on metabolic and endocrine function. Lancet. 1999;354(9188):1435-9 ([Cited 2020 Nov 15]. Available from:http://www.thelancet.com/article/\$01406736990137 68/fulltext).

39. Spiegel K, Leproult R, Van Cauter E. Impact of sleep debt on metabolic and endocrine function. Lancet. 1999;354(9188):1435-9 ([Cited 2020 Nov 15]. Available from:https://doi.org/10.1016/j.sleep.2018.12.014).

40. Sekine M, Yamagami T, Handa K, Saito T, Nanri S, Kawaminami K, et al. A dose-response relationship between short sleeping hours and childhood obesity: Results of the Toyama birth cohort study. Child Care Health Dev. 2002;28(2):163-70. ([Cited 2020 Aug 28]. Available from:https://doi.org/ 10.1046/j.1365-2214.2002.00260.x).

41. Bediz CS, Baltaci AK, Mogulkoc R. Both zinc deficiency and supplementation affect plasma melatonin levels in rats. Acta Physiol Hung. 2003;90(4):335-9 ([Cited 2020 Sep 8]. Available from:https://pubmed. ncbi.nlm.nih.gov/14708876/).

42. Peuhkuri K, Sihvola N, Korpela R. Dietary factors and fluctuating levels of melatonin. Food Nutr Res. 2012;56(1):17252 ([Cited 2020 Aug 10]. Available from:http://foodandnutritionresearch.net/index.php/fnr/article/ view/471).

43. Das JK, Salam RA, Thornburg KL, Prentice AM, Campisi S, Lassi ZS, et al. Nutrition in adolescents: physiology, metabolism, and nutritional needs. Ann NY Acad Sci. 2017;1393:21-33. Available from: https://doi.org/10. 1111/nyas.13330.

44. Godos J, Grosso G, Castellano S, Galvano F, Caraci F, Ferri R. Association between diet and sleep quality: A systematic review. Sleep Med Rev. 2021;57:101430.

45. Wu W, Zhao A, Szeto IM-Y, Wang Y, Meng L, LiT et al. Diet Quality, Consumption of Seafood and Eggs Are Associated with Sleep Quality Among Chinese Urban Adults: A Cross-Sectional Study in Eight Cities of China | Enhanced Reader. Food Sci Nutr. 2019;7:2091-102. Available from: https://doi.org/10.1002/fsn3.1050.

46 Shrimpton R, Rokx C. The double burden of malnutrition A Review of Global Evidence. 2012.

47. AggeuMagalhães $P$, Av Professor, MoraesRego F, Paula de Souza N, Israel Cabral de Lira P, Fontbonne A, Cristina de Lima Pinto F, et al. (Mal)nutrition and the new epidemiological trend in a context of development and inequalities. Ciênc saúde coletiva. 2017;22:2257-66.

48. Güngör NK. Overweight and obesity in children and adolescents. JCRPE J Clin Res Pediatr Endocrinol. 2014;6(3):129-43.

\section{Publisher's Note}

Springer Nature remains neutral with regard to jurisdictional claims in published maps and institutional affiliations.

Ready to submit your research? Choose BMC and benefit from:

- fast, convenient online submission

- thorough peer review by experienced researchers in your field

- rapid publication on acceptance

- support for research data, including large and complex data types

- gold Open Access which fosters wider collaboration and increased citations

- maximum visibility for your research: over 100M website views per year

At BMC, research is always in progress.

Learn more biomedcentral.com/submissions 